\title{
Shape of glass and amount of alcohol poured: comparative study of effect of practice and concentration
}

Brian Wansink, Koert van Ittersum

Cornell University,

Ithaca, NY

14853-7801, USA

Brian Wansink

John S Dyson chair of

marketing and

applied economics

College of

Management,

Georgia Institute of

Technology, Atlanta

GA 30332, USA

Koert van Ittersum

assistant professor of

marketing

Correspondence to:

B Wansink

wansink@cornell.edu

BMJ 2005;331:1512-4

\begin{abstract}
Objective To determine whether people pour different amounts into short, wide glasses than into tall, slender ones.

Design College students practised pouring alcohol into a standard glass before pouring into larger glasses; bartenders poured alcohol for four mixed drinks either with no instructions or after being told to take their time.

Setting University town and large city, United States. Participants 198 college students and 86 bartenders. Main outcome measures Volume of alcohol poured into short, wide and tall, slender glasses.

Results Aiming to pour a "shot" of alcohol (1.5 ounces,
\end{abstract} $44.3 \mathrm{ml})$, both students and bartenders poured more into short, wide glasses than into tall slender glasses (46.1 $\mathrm{ml} v 44.7 \mathrm{ml}$ and $54.6 \mathrm{ml} v 46.4 \mathrm{ml}$, respectively). Practice reduced the tendency to overpour, but not for short, wide glasses. Despite an average of six years of experience, bartenders poured $20.5 \%$ more into short, wide glasses than tall, slender ones; paying careful attention reduced but did not eliminate the effect. Conclusions To avoid overpouring, use tall, narrow glasses or ones on which the alcohol level is premarked. To avoid underestimating the amount of alcohol consumed, studies using self reports of standard drinks should ask about the shape of the glass.

\section{Introduction}

Variations in pouring and drinking behaviour mean that the amount of alcohol consumed from a mixed drink can vary widely. ${ }^{1-4}$ Although correction efforts have been suggested, ${ }^{56}$ an important unaccounted source of bias in self reported consumption of spirits may have to do with the shape of the glass into which a drink is poured.

Two of the most common shapes of glasses for spirits are elongated "highball" glasses and short, wide "tumblers." In one study, adults poured 28\% more breakfast juice into short, wide glasses than into slender ones holding the same volume. ${ }^{7}$ This is the result of two perceptual biases: people generally estimate that tall glasses hold more liquid than wide ones of the same volume, ${ }^{89}$ and they focus their pour-

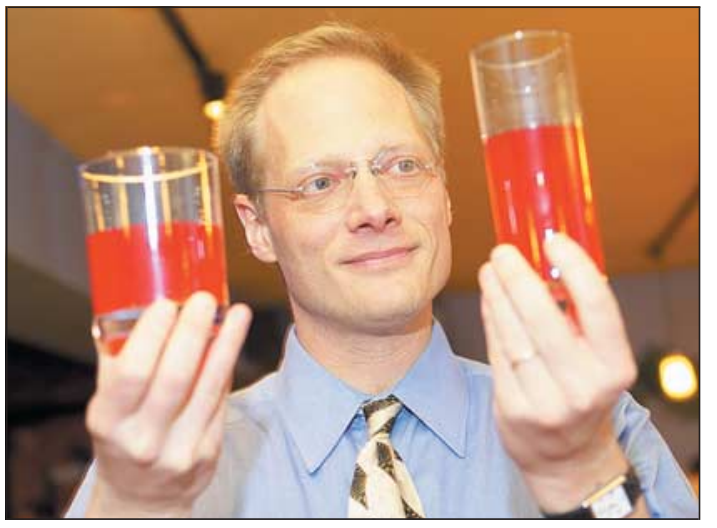

ing attention on the height the liquid reaches and insufficiently compensate for the width of the glass. ${ }^{7}$

Suppose a person wanted to pour a target volume of alcohol, such as a $44.3 \mathrm{ml}$ (1.5 ounce) "shot." The perceptual bias caused by this interaction of vertical and horizontal dimensions could lead to unknowingly pouring more alcohol into a short, wide glass than into a tall, slender glass.

Because people generally consume most (about $92 \%)$ of what they have served themselves, ${ }^{10}$ this issue of pouring accuracy is relevant to policy makers, health professionals, responsible consumers, law enforcement, and those interested in alcohol addiction and misuse. We examined whether practice in pouring or whether increased concentration can help reduce this potential bias.

\section{Methods}

\section{Practice in pouring alcohol}

We recruited 198 students of legal drinking age from the University of Illinois at Urbana-Champaign (57\% men) through courses in various faculties. They were given partial course credit for their involvement in the study, which had been approved by the university.

A $2 \times 2$ between subjects design manipulating shape of glass (short and wide $v$ tall and slender) and pouring education and practice (low $v$ high) was examined across four different drink replications. As participants arrived at the study, they were alternately assigned to

Table 1 Shape of glass and amount of alcohol poured by college students after one or 10 trial pours

\begin{tabular}{|c|c|c|c|c|c|c|c|c|c|c|c|c|}
\hline \multirow[b]{3}{*}{ Variable } & \multicolumn{6}{|c|}{ Mean (SD) amount (ml) } & \multicolumn{6}{|c|}{ Significance } \\
\hline & \multicolumn{3}{|c|}{ Tall, slender glass } & \multicolumn{3}{|c|}{ Short, wide glass } & \multicolumn{2}{|c|}{ Glass shape } & \multicolumn{2}{|c|}{ Experience } & \multicolumn{2}{|c|}{$\begin{array}{c}\text { Glass shape } \times \\
\text { experience }\end{array}$} \\
\hline & 1 trial & 10 trials & Average & 1 trial & 10 trials & Average & $\begin{array}{c}F \\
\text { value }\end{array}$ & $\begin{array}{c}\mathrm{P} \\
\text { value }\end{array}$ & $\begin{array}{c}F \\
\text { value }\end{array}$ & $\begin{array}{c}P \\
\text { value }\end{array}$ & $\begin{array}{c}F \\
\text { value }\end{array}$ & $\begin{array}{c}P \\
\text { value }\end{array}$ \\
\hline $\begin{array}{l}\text { Perceived capacity of } \\
\text { glass }\end{array}$ & $356.5(221.1)$ & $336.4(145.1)$ & 346.7 & $333.7(137.1)$ & $325.8(138.5)$ & 329.9 & 5.46 & $<0.01$ & 0.64 & 0.59 & 0.51 & 0.68 \\
\hline \multicolumn{13}{|l|}{ Volume poured: } \\
\hline Actual & $48.9(16.2)$ & $42.2(13.3)$ & 45.5 & $60.9(17.9)$ & $57.3(18.0)$ & 59.6 & 31.89 & $<0.01$ & 4.08 & $<0.01$ & 0.36 & 0.78 \\
\hline Perceived & $46.3(3.8)$ & $45.9(2.9)$ & 46.1 & $44.7(4.2)$ & $44.6(4.2)$ & 44.6 & 7.03 & $<0.01$ & 0.38 & 0.77 & 0.25 & 0.88 \\
\hline
\end{tabular}




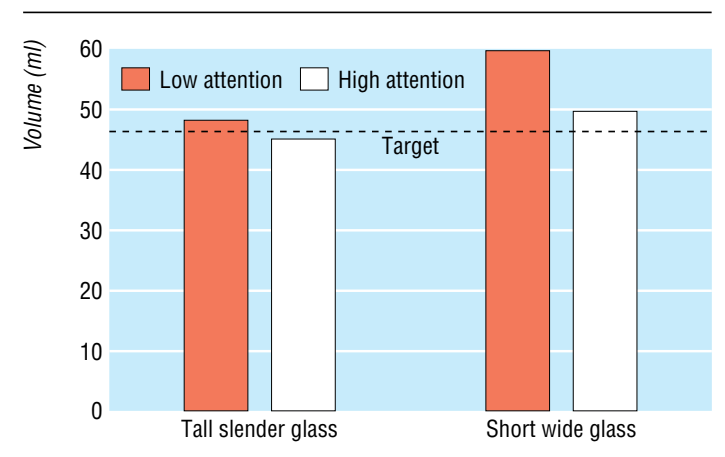

Pouring by bartenders into glasses of different shapes

one of the practice conditions. In the low pouring education and practice condition, participants conducted one practice pour into a 1.5 ounce shot glass, after which the pouring for the experiment began. Participants in the high education condition were asked to conduct 10 practice pours before beginning the pouring for the experiment.

Participants were supplied with full $1500 \mathrm{ml}$ rum and whiskey bottles that had been refilled with brown tea and with $1500 \mathrm{ml}$ gin and vodka bottles that had been refilled with water. Half of the participants were given tall, slender $355 \mathrm{ml}$ glasses and half were given short, wide $355 \mathrm{ml}$ glasses. Participants were asked to pour the amount of liquor that would go into four mixed drinks that were popular at the college-vodka tonic, rum and Coke, whiskey on the rocks, and gin and tonic. They should have poured $44.3 \mathrm{ml}$ (1.5 ounces) for each of the drinks. After pouring all of the drinks, participants were asked to estimate how much they thought they had poured, and the volume actually poured was measured.

After a distraction task, the participants were shown the tumbler and the highball glass in a rotated order and asked to estimate the total capacity of each glass.

Analysis of variance indicated that the type of drink and the interactions between the type of drink and the independent variables and covariates were not significant $(\mathrm{P}>0.10)$ for either the actual or the perceived volumes poured. Because none of the covariates had a main effect on the amount of liquor poured $(\mathrm{P}>0.10)$, the data were pooled.

\section{Attention to pouring alcohol}

Of 95 Philadelphia bartenders (62\% men) who were approached on a Sunday or Monday evening and offered $\$ 4.00$ ( $£ 2.30, € 3.40)$ to take part in a study on "alcohol and other consumer behaviour related issues," 86 agreed to participate ( $62 \%$ men). They had an average of 6.3 years of bartending experience.
A $2 \times 2$ between subjects design manipulated glass shape (short and wide $v$ tall and slender) and the amount of attention (low $v$ high) allocated to the pouring task. Each bartender was asked to pour the established standard amount of alcohol (44.3 ml) using $1500 \mathrm{ml}$ bottles and glasses as in the study of college students.

Bartenders in the low attention condition were simply asked to pour the amount of rum in a rum and Coke, the amount of gin in a gin and tonic, the amount of vodka in a vodka tonic, and the amount of whiskey in a whiskey on the rocks. The order in which they were asked to pour the drinks was randomised. Bartenders in the high attention condition were asked to pour the same four drinks, but the experimenter encouraged them to "please take your time" before they poured each drink. After this, they were asked to indicate on a nine point scale whether they agreed with the statement that they "had paid close attention to how much they poured."

A repeated measures analysis of variance indicated that there were no main effects or interactions across the types of drinks or the order poured, so the data were pooled.

\section{Results}

\section{Practice in pouring alcohol}

Overall, the college students believed the tall, slender $355 \mathrm{ml}$ glasses held significantly more than the short, wide 355 ml glasses (mean 346.7 v $329.9 \mathrm{ml} ; \mathrm{P}<0.05$, table 1), and this visual estimation bias corresponded to an opposite bias when they were pouring. They poured 30\% more into short, wide glasses than tall, slender glasses (59.1 $v 45.5 \mathrm{ml} ; \mathrm{P}<0.01)$. The general tendency to pour more than a $44.3 \mathrm{ml}$ shot was greatest with short, wide glasses, but participants who poured into these glasses believed they poured less than those who poured into the tall, narrow glasses (44.6 $246.1 \mathrm{ml} ; \mathrm{P}<0.01)$.

The shape of glasses continued to influence those who had done 10 practice pours only moments earlier (42.2 v $60.9 \mathrm{ml} ; \mathrm{P}<0.01)$. Although practice reduced the tendency to overpour into tall glasses (48.9 $v 42.2$ $\mathrm{ml} ; \mathrm{P}<0.05$ ), it did not do so for the short, wide glasses (60.9 $57.3 \mathrm{ml} ; \mathrm{P}>0.10)$.

\section{Attention to pouring alcohol}

Bartenders in the high attention condition took about twice as long to pour each drink as those in the low attention condition (mean $3.7 v 1.9$ seconds; $\mathrm{P}<0.001$ ), and they agreed more strongly with the statement that they "had paid close attention to how much they poured" (mean score 2.0 v 7.1 (maximum 9); $\mathrm{P}<0.01$ ).

Table 2 Shape of glass and amount of alcohol poured by bartender under low attention and high attention conditions

\begin{tabular}{|c|c|c|c|c|c|c|c|c|c|c|c|c|}
\hline \multirow[b]{3}{*}{ Drink } & \multicolumn{6}{|c|}{ Mean (SD) amount poured (ml) } & \multicolumn{6}{|c|}{ Significance } \\
\hline & \multicolumn{3}{|c|}{ Tall, slender glass } & \multicolumn{3}{|c|}{ Short, wide glass } & \multicolumn{2}{|c|}{ Glass shape } & \multicolumn{2}{|c|}{ Attention } & \multicolumn{2}{|c|}{$\begin{array}{l}\text { Attention } \times \\
\text { glass shape }\end{array}$} \\
\hline & $\begin{array}{c}\text { Low } \\
\text { attention }\end{array}$ & $\begin{array}{c}\text { High } \\
\text { attention }\end{array}$ & Average & $\begin{array}{c}\text { Low } \\
\text { attention }\end{array}$ & $\begin{array}{c}\text { High } \\
\text { attention }\end{array}$ & Average & $F$ value & $P$ value & $F$ value & $P$ value & F value & $P$ value \\
\hline All drinks & $47.9(2.6)$ & $44.9(2.4)$ & 46.4 & $59.4(10.8)$ & 49.7 (3.7) & 54.6 & 31.91 & $<0.01$ & 20.19 & $<0.01$ & 9.16 & $<0.01$ \\
\hline Rum & $48.1(2.6)$ & $45.2(3.6)$ & 46.7 & $60.2(11.3)$ & $48.4(4.9)$ & 54.3 & 24.43 & $<0.01$ & 22.44 & $<0.01$ & 11.86 & $<0.01$ \\
\hline Vodka & $47.5(2.9)$ & $44.6(3.0)$ & 46.0 & $59.4(9.9)$ & $49.8(4.9)$ & 54.6 & 37.38 & $<0.01$ & 20.77 & $<0.01$ & 10.23 & $<0.01$ \\
\hline Whiskey & $46.9(3.8)$ & $44.7(3.0)$ & 45.8 & $58.7(11.2)$ & $50.8(5.0)$ & 54.8 & 29.81 & $<0.01$ & 10.58 & $<0.01$ & 5.88 & $<0.05$ \\
\hline Gin & $49.1(4.7)$ & $45.0(4.2)$ & 47.1 & $59.5(13.8)$ & $49.8(6.6)$ & 54.7 & 15.15 & $<0.01$ & 12.82 & $<0.01$ & 3.68 & 0.08 \\
\hline
\end{tabular}


More experienced bartenders poured an average of $10.3 \%$ less alcohol than less experienced bartenders (48.2 v $53.1 \mathrm{ml} ; \mathrm{P}<0.05)$.

Despite an average of 6.3 years of experience, bartenders poured $20.5 \%$ more into short, wide glasses than tall, slender glasses (55.5 v $46.1 \mathrm{ml} ; \mathrm{P}<0.001)$ (figure). The normative bias was to overpour into short, wide glasses rather than to underpour into tall, slender glasses (table 2).

Bartenders who paid less attention while pouring poured more into the short, wide glasses than into the tall, slender glasses $(59.4 v 47.9 \mathrm{ml} ; \mathrm{P}<0.01)$. If they paid careful attention while pouring, the effect was reduced ( $49.7 v 44.9 \mathrm{ml} ; \mathrm{P}<0.01)$ but not eliminated.

\section{Discussion}

Although people believe they have poured more into a tall, slender glass, even professional bartenders unknowingly pour $20-30 \%$ more alcohol into short, wide glasses than into tall, slender ones. This bias is only slightly reduced by practice, concentration, or experience. Although our studies focused on pouring, both laboratory and field studies show that what is typically poured is typically drunk, ${ }^{11}$ especially when served by a bartender. ${ }^{12}$

\section{Implications for controlling alcohol consumption}

This 20-30\% overpouring that glass shapes can encourage needs to be accounted for in analyses of self reports of "standard" drinks. In a large epidemiological study, alcohol consumption per glass could be under-reported by as much a quarter. To account for or to correct such biases, additional questions should be added to surveys that use self reports. People drinking spirits should be asked the type or shape of glasses they typically drink from (short and wide or tall and slender), and they should be asked whether they pour freehand or with the help of a measurement aid (such as a shot glass). This information can then be used to adjust reported alcohol consumption to better reflect the actual level of consumption.

A wide range of people would like better control of alcohol consumption because of the negative consequences related to overconsumption. Those in the hospitality industry want to decrease costs (via serving size) without decreasing satisfaction. Those in public policy want to increase safety. Those dealing with alcohol counselling want to increase responsible drinking and decrease alcohol misuse.

\section{What is already known on this topic}

People pour 20-30\% more into short, wide glasses than into tall, slender glasses, but they wrongly believe that tall glasses hold more

\section{What this study adds}

Bartenders poured 20\% more into tumblers than into highball glasses of the same volume

Studies using self reports of "standard drinks" should ask questions about the shape of the glass

Two easy solutions to overpouring are to use or request tall, slender glasses or to use glasses on which the alcohol level is marked

If short tumblers lead even bartenders to pour more alcohol than tall highball glasses, the way to better control alcohol consumption is to use tall glasses or to use glasses with the alcohol level marked on them-and to realise that, when alcoholic drinks are served in a short wide glass, two drinks are actually equal to two and a half.

$\mathrm{BM}$ and $\mathrm{KvI}$ both contributed to design, data collection, analysis, and writing of the paper, and are guarantors.

Funding: None.

Competing interests: None declared.

Ethical approval: Standard consent forms were signed and were sufficient for institutional approval.

1 Lemmens PH. The alcohol content of self-report and "standard" drinks. Addiction 1994;89:593-601

2 Carruthers SJ, Bilnns CW. The standard drink and alcohol consumption. Drug Alcohol Rev 1992;11:363-70.

3 Lemmens PH, Tan ES, Knibbe RA. Measuring quantity and frequency of drinking in a general population survey: a comparison of 5 indices.J Stud Alcohol 1992;53:476-86.

Turner C. How much alcohol is in a "standard drink"? Br J Addiction 1990;85:1171-5.

5 Miller WR, Heather N, Hall W. Calculating standard drink units: international comparisons. Br JAddiction 1991;86:43-7.

6 Stockwell T, Stirling L. Estimating alcohol content of drinks: common Stockwell I, Stirling L. Estimating alcohol content of
errors in applying the unit system. BMJ 1989;198:571-2.

7 Wansink B, Van Ittersum K. Bottoms up! The influence of elongation on pouring and consumption volume.J Consumer Res 2003;30:455-63.

8 Piaget J. The mechanisms of perception. London: Routledge \& Kegan Paul, 1969.

9 Raghubir P, Krishna A. Vital dimensions in volume perception: can the eye fool the stomach? J Marketing Res 1999;36:313-26.

10 Wansink B, Cheney MM. Super bowls: serving bowl size and food consumption. JAMA 2005;293:1727-8.

11 Wansink B. Can package size accelerate usage volume? J Marketing 1996;60(3):1-16.

12 Stockwell T, Blaze-Temple D, Walker C. The effect of "standard drink" labeling on the ability of drinkers to pour a "standard drink." Aust J Public Health 1991;15:56-63.

\section{Just say "No"}

I was amused by a consent quandary that arose as I was about to anaesthetise a patient. Her wristband with the exaltation "Say No To Drugs" was at odds with my objective to administer potent substances intravenously through the device immediately below it. After a brief discussion, agreement was reached that I should proceed.

James Craggs consultant anaesthetist, Lincoln County Hospital,Lincoln (james.craggs@ulh.nhs.uk)

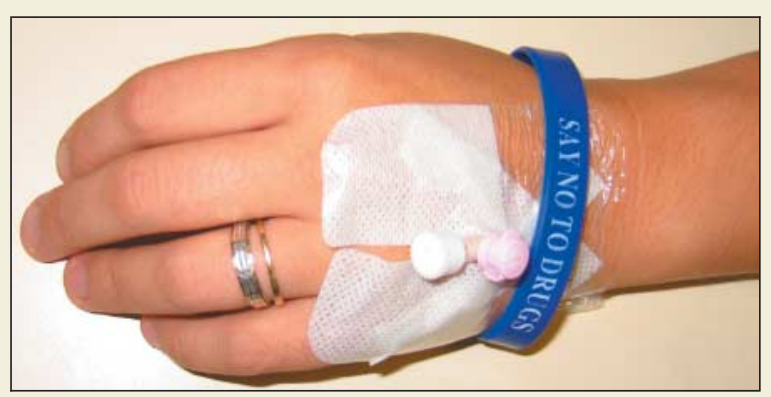

